\title{
Virtual Simulation Method in Hospital Design
}

\author{
Muchammad Amien ${ }^{1}$, Murni Rachmawati ${ }^{1}$, and Muhammad Faqih ${ }^{1}$
}

\begin{abstract}
The development of computing technology affords wide opportunities to apply the virtual reality in the building design process. Virtual reality not only promotes possibilities to explore architectural forms but also affords capability to learn the interaction of users and the design object as if they do in the real situation. User reaction toward design model can be learned and used to be effective information to develop a promoted preliminary design. The user satisfaction and suitability are indicated by their feedback of design object in virtual reality simulation. This paper aims to explain the application of the method on hospital building design. In this case the authors found that the method is very accurate to capture the user need and very valuable to support design process.
\end{abstract}

Keywords-Behavior, Design method, Simulation, Virtual reality.

\section{INTRODUCTION}

Virtual reality means to have the effect of concrete existence without actually having concrete existence [1]. It achieve by using computers software to simulate a three-dimensional interactive world with spatial depth. The applications have a wide range uses from entertainment to research. Virtual reality can be used to watch $3 \mathrm{D}$ cinema even in micro dimension research on the chemical structure.

Simulation methods do not always have to use virtual reality. Object replication in the simulation method itself doesn't need to have spatial deep. For example simulating the relationship between supply and demand can be created in two-dimensional graph curve. Virtual reality simulation methods used its full potential when the simulation requires a human perspective with spatial depth. As an example of simulation training emergency landing on water, this kind of simulation is able to provide an understanding of the emergency landing procedures on simulated participants [2].

In this seminar, virtual simulation method is applied to hospital building design. The reason for choosing the hospital as a study case due the complexity of the hospital management.

The intended use of virtual reality is to examine the accuracy of the draft program to the needs of the user. The needs of the user is meant is the suitability of the rooms dimension to human perception. The second is the ability to maneuver healthcare providers, patients, and the items in a space designed. The third is a spatial pattern in its function to serve the medical service activities. Lastly is the perception of medical personnel on the completeness of the equipment in the room.

From virtual reality simulation obtained feedback from users in the form of responses to the design. Feedback can design the form of advice on design development or response to the design that has been created. Based on the feedback obtained is used to develop the design further towards conformity with the user.

Virtual reality was originally conceived as a digitally created space that humans could access by donning sophisticated computer equipment [3].

The theory used to discuss methods of virtual reality is theory of behavior setting introduced by John Zeisel in 1984. This theory see virtual reality method from architecture psychology.

In the process of design information environment behavior can be seen as a circle cycle of a project that includes research users, grounding decision, programing, alternatives of design, selection, design development, management environment, evaluation of the use and feedback to the research, decision-making and programing [4].

\section{METHOD}

Based on the design process initiated by John Zeisel is "Environment - behavior studies in the design process" stated that the design with the right result to go through several cycles of design. The needs of the design process that requires more than one design cycle can be cut by using virtual reality technology.

In virtual reality simulation is necessary to determine the patterns of interaction that occur within the simulation, namely:
a. Colliding
b. Interaction
c. Visualization

In colliding, Users must use a reference when moving or floating floor. Users should not walk through walls. This means setting a limit to the space and scope of users in virtual reality simulations. In interaction, User can interact with objects in the simulation. How users interact with the door, opening and closing doors. In Visualization, Users viewed space interactively with have depth perception.

How users interact with the virtual environment affects the realism of virtual reality. That's why in the virtual reality simulation, design should be made in detail.

In this virtual reality simulation created using the unreal engine version of 4.10 with the following results.

To create deep cue in this simulation then oculus rift device used as the base.

In the hospital virtual reality simulation has been able to show some as following:
a. Architectural impression.
b. Dimensional space.
c. Circulation in the room.
d. The instrument function in the room.

The expected results of this simulation method can be measured is the level of conformity to the user in terms of design are the medical staff. To get the respondent data

${ }^{1}$ Muchammad Amien, Murni Rachmawati, and Muhammad Faqih are with Department of Architecture, Institut Teknologi Sepuluh Nopember, Surabaya, Indonesia. E-mail: muchammad.amien@gmail.com; murnirach@arch.its.ac.id; faqih@arch.its.ac.id. 
through qualitative interviews. The respondents were from the hospital as follows:
a. Regional General Hospital of West Sulawesi Province
b. Hospital Syarifah Ambami Ratoh Ebuh Bangkalan, Madura, East Java.
c. Naval Hospital Dr. Ramelan Surabaya, East Java

\section{RESULTS AND DISCUSSION}

Based on 12 interviews of respondents, interviews were conducted to obtain qualitative data related to the impression of vast space, workplace maneuver in space, workflow has been arranged properly, and with appropriate equipment in space. The data obtained are as follows:
Base on responded feedback it can be seen that the design concept presented sufficient to meet the needs of medical personnel.

Virtual reality is a powerful tool to confirm design result related to user physiology. The ability of virtual reality is to simulate a human standpoint which mean human behavior can be simulated in a controlled environment. By combining virtual reality and right question this method can be used to confirm the user reaction to the design.

In virtual reality study of hospital design it can be assured that design result fit to user need. Based on respondent answer query which indicate users accept the design result. Majority of response in middle column which mean good enough.

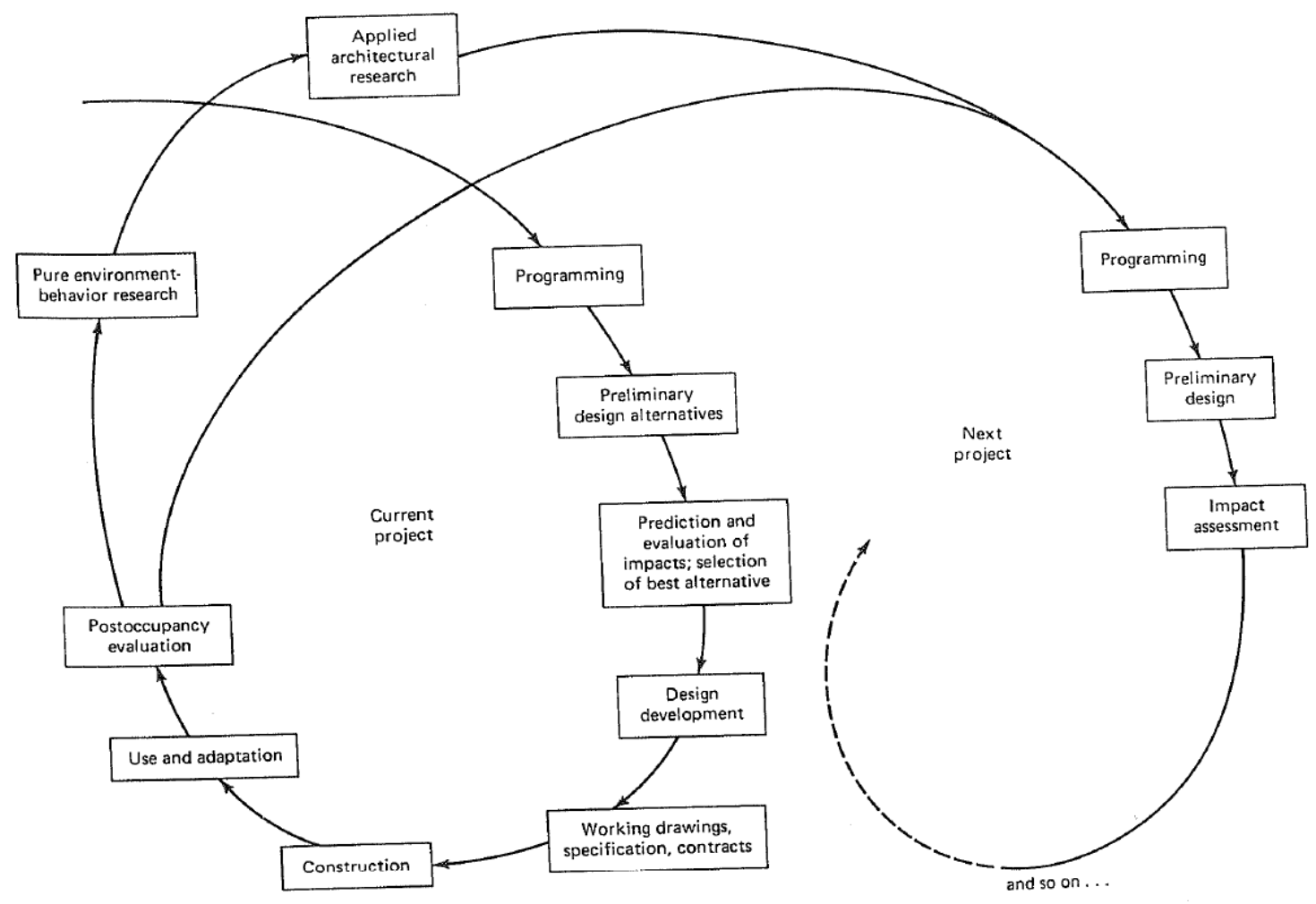

Figure. 1. Environment - Behavior Studies In the Design Process. (Source: Inquiry by Design, John Zeisel, 1984)

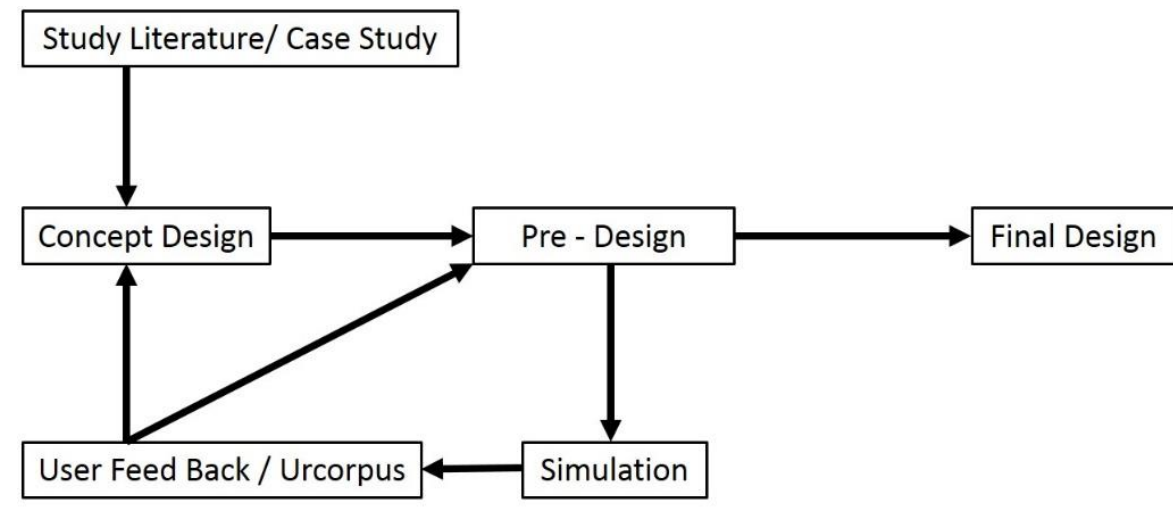

Figure. 2. Virtual Reality Design Process 
The $2^{\text {nd }}$ International Seminar on Science and Technology August $2^{\text {nd }} 2016$, Postgraduate Program Institut Teknologi Sepuluh Nopember, Surabaya, Indonesia

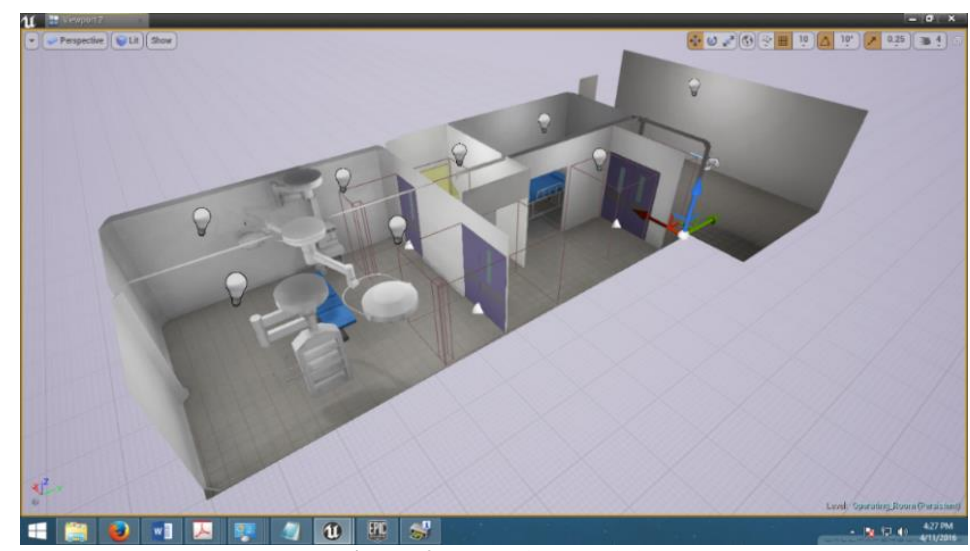

Figure 3. Operating Module

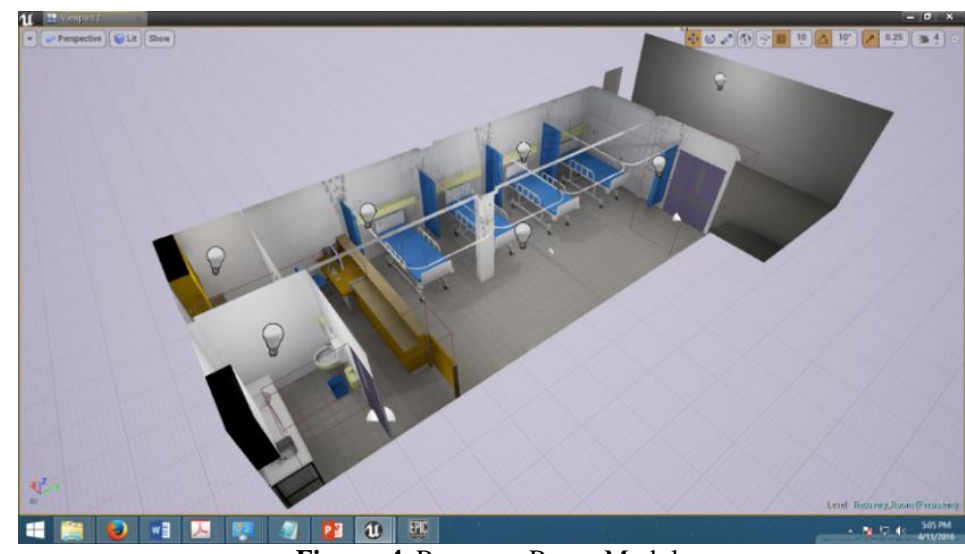

Figure. 4. Recovery Room Module

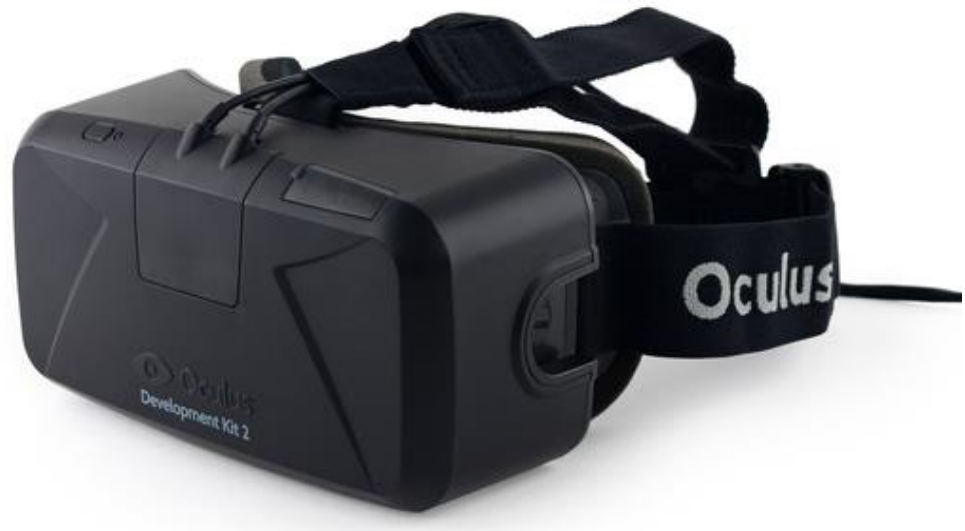

Figure. 5. Oculus Rift (Source: http://www.oculus.com)

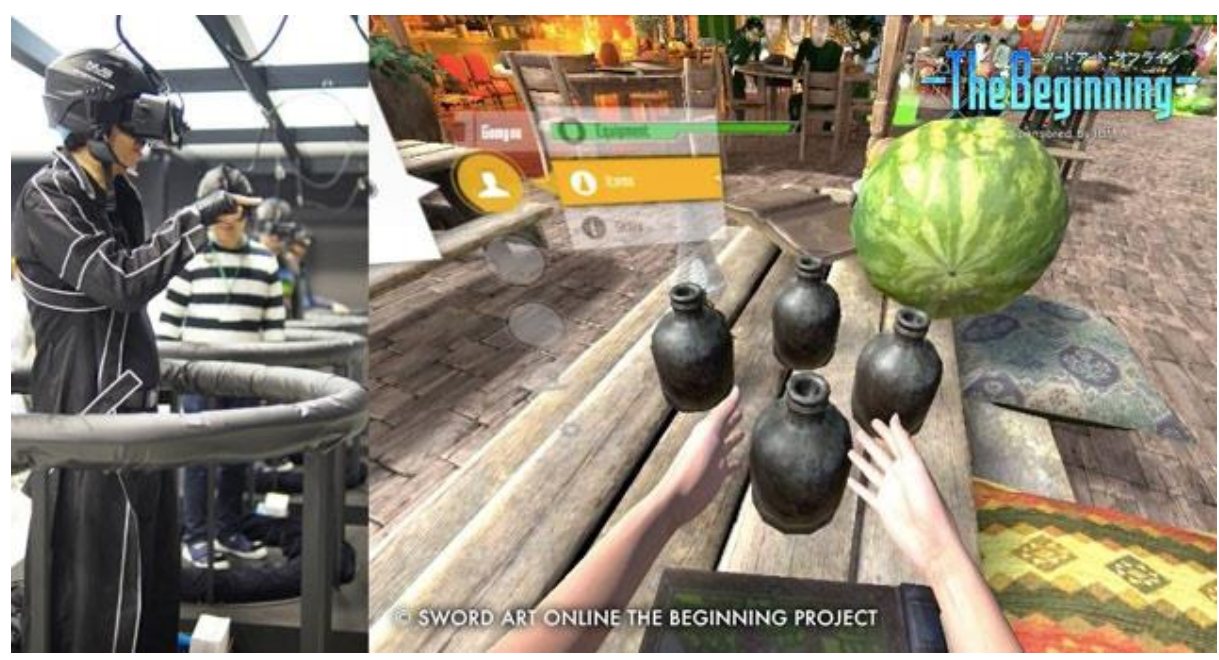

Figure. 6. . Oculus Rift User (Source: http://news.mmosite.com) 
The $2^{\text {nd }}$ International Seminar on Science and Technology

August $2^{\text {nd }}$ 2016, Postgraduate Program Institut Teknologi Sepuluh Nopember, Surabaya, Indonesia

TABLE 1.

REgional General Hospital of West Sulawesi PRovince.

\begin{tabular}{lccc}
\multicolumn{4}{l}{ REGIONAL GENERAL HOSPITAL OF WEST SULAWESI PROVINCE. } \\
\hline \hline & Good & Enough & Less \\
\hline Vast size of space? & 1 & 3 & 1 \\
Maneuver work in space? & 0 & 4 & 1 \\
Flow for medical activities? & 1 & 4 & 0 \\
Completeness tool? & 0 & 5 & 0 \\
\hline \hline
\end{tabular}

TABLE 2.

HoSPITAL SYARIFAH AMBAMI RATOH EBUH BANGKALAN, MADURA, EAST JAVA.

\begin{tabular}{lccc}
\hline \hline & Good & Enough & Less \\
\hline Vast size of space? & 1 & 3 & 2 \\
Maneuver work in space? & 0 & 2 & 4 \\
Flow for medical activities? & 2 & 4 & 0 \\
Completeness tool? & 1 & 3 & 2 \\
\hline \hline
\end{tabular}

TABLE 3.

NAVAL HospitAL DR. RAMELAN SURABAya, EAST JAVA.

\begin{tabular}{lccc}
\hline \hline & Good & Enough & Less \\
\hline Vast size of space? & 0 & 1 & 0 \\
Maneuver work in space? & 0 & 1 & 0 \\
Flow for medical activities? & 1 & 0 & 0 \\
Completeness tool? & 1 & 0 & 0 \\
\hline \hline
\end{tabular}

\section{REFERENCES}

[1] Bryson, S., "Virtual Reality: A Definition History - A Personal Essay," Journal CoRR, 2013.

[2] Chittaro, L., \& Buttussi, F., "Assessing Knowledge Retention of an Immersive Serious Game vs. a Traditional Education Method in Aviation Safety," Journal Visualization and Computer Graphics, vol.21, no.4, 529-538, 2015.
[3] Lanier, J., S. A., "Virtual reality: The promise of the future," Interactive Learning International, 1992.

[4] Zeisel, J., Inquiry by Design. Cambridge: Cambridge University Press, 1984 